livraisons

d'Histoire

de l'Architecture

\section{Livraisons de l'histoire de l'architecture}

42 | 2021

2001-2021 / numéro anniversaire

\title{
Notices biographiques
}

\section{Q OpenEdition}

\section{Journals}

Édition électronique

URL : https://journals.openedition.org//ha/3830

DOI : $10.4000 /$ /ha.3830

ISSN : 1960-5994

Éditeur

Association Livraisons d'histoire de l'architecture - LHA

Référence électronique

" Notices biographiques », Livraisons de l'histoire de l'architecture [En ligne], 42 | 2021, mis en ligne le 11 décembre 2021, consulté le 11 décembre 2021. URL : http://journals.openedition.org//ha/3830 ; DOI : https://doi.org/10.4000/lha.3830

Ce document a été généré automatiquement le 11 décembre 2021.

Tous droits réservés à l'Association LHA 


\section{Notices biographiques}

1 Agrégée d'histoire, Conservatrice en chef du patrimoine honoraire, docteur de l'E.P.H.E., Arlette Auduc a occupé, de 2006 à 2015, le poste de conservateur régional de l'inventaire, chef du service Patrimoines et Inventaire à la Région Île-de-France. Elle poursuit ses recherches sur l'histoire de la protection du patrimoine et sur les relations patrimoines et territoires. Correspondante patrimoine du Comité d'histoire du ministère de la culture, elle s'intéresse plus particulièrement à l'histoire des politiques publiques menées dans ce domaine. Parmi ses publications : "Quand les monuments construisaient la nation. Le service des Monuments historiques de 1830 à 1940 », Comité d'histoire du ministère de la culture/Documentation française, 2008. 640 p. Ces patrimoines qui font territoires (dir.), actes du colloque régional de novembre 2011, Somogy Éditions d'art, 2012 . «La mise en mouvement de la loi de 1913 : l'approche de l'administration, la figure de Paul Léon et le service de l'architecture », "L'évolution des services territoriaux et les monuments historiques", "Inventaire général de patrimoine culturel et aménagement du territoire : l'exemple de l'île-de-France », in De 1913 au Code du patrimoine. Une loi en évolution sur les monuments historiques, Jean-Pierre Bady, Marie Cornu, Jérôme Fromageau, Jean-Michel Leniaud, Vincent Négri, dir. Comité d'histoire du ministère de la culture/Documentation française, 2013, p. 24-31 ; 207-213. Depuis 2017, elle est rédactrice en chef des Livraisons d'histoire de l'architecture (LHA).

2 Aurélien Bellanger, né à Laval, en 1980, est romancier. Il est l'auteur de La théorie de l'information (2012), de L'aménagement du territoire (2014), du Grand Paris (2017), du Continent de la douceur (2019) et de Téléréalité (2021), tous parus aux éditions Gallimard. Il a également tenu, pendant quatre ans, une chronique quotidienne sur France Culture, dont quelques-unes ont paru dans un recueil appelé : La France (2019). Il a enfin publié un essai, Michel Houellebecq écrivain romantique (2010) et une pièce de théâtre, Eurodance (2018).

Marie Cornu est directrice de recherches au CNRS affectée à l'ISP (Institut des Sciences sociales du politique, UMR 7220, ENS Paris Saclay, Université Paris X Nanterre). Ses thématiques portent en grande partie sur le droit du patrimoine ainsi que sur les rapports entre langue et droit et plus généralement sur l'évolution des figures de la propriété. Elle a publié : Le droit culturel des biens, l'intérêt culturel juridiquement protégé, Bruylant, 1996 et co-dirigé plusieurs ouvrages collectifs notamment le Dictionnaire de 
droit comparé du droit du patrimoine culturel, co-auteurs Jérôme Fromageau, Catherine

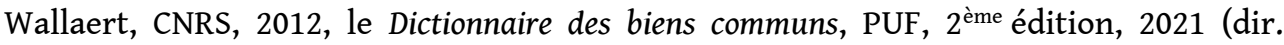
M. Cornu, F. Orsi, J. Rochfeld), et dans le cadre du projet Mémoloi, 1913, genèse d'une loi sur les monuments historiques, 2013 et De 1913 au Code du patrimoine, une loi en évolution, 2018, (dir. J.-P. Bady, M. Cornu, J. Fromageau, J.-M. Leniaud, V. Négri), 1979, genèse d'une loi (dir. M. Cornu, Y. Potin, B. Ricard, N. Wagener), Comité d'histoire du ministère de la Culture, documentation française, «La mort des cathédrales, Marcel Proust et la séparation des Églises et de l'État », Revue Droit \& Littérature, 2021/1 (n 5), p. 177-194.

4 Christian Hottin, est archiviste paléographe (1997) et conservateur du patrimoine (2001). Après avoir travaillé aux Archives nationales et dans l'administration centrale du ministère de la culture (Mission du patrimoine ethnologique), il a rejoint en 2016 l'Institut national du patrimoine en tant que directeur des études, chargé du département des conservateurs, de la programmation scientifique et culturelle et des publications. Ses recherches ont porté notamment sur l'architecture publique au XIXe et $\mathrm{XX}^{\mathrm{e}}$ siècle. Il a soutenu le 23 novembre 2021 une thèse de l'Université PSL préparée à l'E.P.H.E. (IV ${ }^{e}$ section), sous la direction de JeanMichel Leniaud et consacrée aux patrimoines de l'enseignement supérieur à Paris.

5 Ivan Jablonka, historien, écrivain et éditeur, est professeur à l'université Sorbonne Paris Nord, membre de l'Institut universitaire de France. Il a notamment publié, aux Éditions du Seuil, Histoire des grands-parents que je n'ai pas eus (prix du Sénat du livre d'histoire 2012), Laëtitia ou la fin des hommes (prix Médicis 2016) et En camping-car (prix France Télévisions 2018). Ses livres sont traduits dans une quinzaine de langues.

6 Jean-Michel Leniaud, né en 1951, a passé les années 1976-1990 au ministère de la Culture dans les services du Patrimoine. De 1990 jusqu'à 2021, il a occupé la conférence d'histoire de l'architecture occidentale des XIX et $\mathrm{XX}^{\mathrm{e}}$ siècles à l'École pratique des hautes études, à la Sorbonne. De 2011 à 2016, il a dirigé l'École nationale des chartes, établissement dans lequel il était aussi professeur d'histoire de l'art de l'époque contemporaine. Il a dirigé et publié de très nombreux ouvrages et est président d'honneur les Livraisons d'histoire de l'architecture.

7 Daniel Payot est professeur émérite de l'Université de Strasbourg et membre de l'UR 3402 ACCRA (Approches contemporaines de la création et de la réflexion artistique). Ses recherches portent principalement sur les théories des arts au $\mathrm{XX}^{\mathrm{e}}$ siècle et sur les écrits de Theodor W. Adorno. Derniers titres parus : Retours d'échos. Comment ne pas écrire sur l'art et les artistes, L'Atelier contemporain, 2020 ; «L'expérience en fragments ", postface à Walter Benjamin, Sens unique, traduction Sybille Muller, Circé, 2021;Constellation et utopie. Theodor W. Adorno, le singulier et l'espérance, Klincksieck, 2018.

8 Pauline Verger, élève de l'École normale supérieure à Paris, est titulaire d'une double licence d'histoire et géographie. Elle est actuellement étudiante du Master 2 de Relations internationales cohabilité par l'Université Paris II Panthéon-Assas et Sorbonne Université. Ses recherches portent sur les liens entre patrimoine culturel et conflits aux $\mathrm{XX}^{\mathrm{e}}$ et $\mathrm{XXI}^{\mathrm{e}}$ siècles. Elle est également engagée au sein de l'association Patrimoine sans frontières pour laquelle elle écrit des articles de sensibilisation sur les grands enjeux du patrimoine. Elle a publié : Pauline Verger, Manon Le Bon, Mathilde Beaufils, Chloé Vincent et Justine Vignères, «Prendre le terrain pour objet: une expérience de recherche collective sur les espaces publics à Ibadan, Nigeria », Carnets de géographes [En ligne], 14|2020; article collectif, «Les nouvelles frontières de la 
défense ", Revue de défense nationale, 2020. Adresse électronique : pauline.verger@ens.psl.eu

9 Annette Viel, muséologue, consultante internationale, a développé une approche originale de mise en valeur patrimoniale y intégrant la notion de respect de l'esprit des lieux. Elle a été professeur (2002-2007) au Muséum National d'Histoire Naturelle de Paris et à l'Université de Bourgogne (1999-2002). Elle a dirigé et collaboré à de multiples projets en muséologie et en patrimoine dans différents pays et continents. Elle prône une approche transdisciplinaire et diversifiée n'hésitant pas à prendre des voies inédites alliant arts et sciences. Elle a publié divers articles qui témoignent d'une nécessité d'œuvrer pour des lieux ouverts sur demain, des lieux incitant les publics à vivre une expérience de sens. En 2012, elle recevait le prix carrière remis par la Société des Musées Québécois (SMQ), précédé en 2008 du prix rayonnement international donné conjointement par l'Association des Musées Canadiens (AMC) et ICOM Canada. En 2018, elle fut nommée Chevalière des Palmes académiques françaises. Elle est membre du Comité scientifique international de la revue Culture \& Musées. 